\title{
Future-proofing simulation and clinical skills
}

\begin{abstract}
Midwifery pre-registration education must adopt a range of learning and teaching approaches, including simulation and clinical skills sessions, to ensure students midwives have the required skills and competencies to be admitted to the register (NMC, 2009). Simulation and clinical skills sessions facilitated in the 'safe' environment of the classroom enhance students understanding, confidence and skills, particularly in relation to the management of obstetric emergencies, where in practice the needs of the woman take precedence over students' learning opportunities. The unpredictability of the clinical environment may lead to students not having the opportunity to manage an obstetric emergency until after they qualify. Setting up and facilitating simulation and clinical skills sessions is time consuming for midwifery lecturers and not best use of their expertise, which is why specialist support in the form of Laboratory/Clinical Skills Technicians is critical to the smooth running of sessions and maintenance of costly equipment.
\end{abstract}

Keywords: simulation; clinical skills; student midwives; competence; obstetric emergencies

Simulation and clinical skills sessions support student midwives in developing their clinical and communication skills and links theory to practice in a safe environment (Yuill, 2017; Lendahls and Oscarsson, 2017). Evidence suggests simulation workshops can increase students' understanding, confidence and clinical abilities which are then consolidated in practice (Catling et al., 2016). This is particularly important for managing emergency situations which are unpredictable in nature and in any event, the wellbeing of the woman and baby must take precedence over students' learning opportunities. This can result in some students not ever having the opportunity to manage an obstetric emergency until post qualification (Yuill, 2017). 
There is a strong rationale for embedding simulation and clinical skills sessions into the pre-registration midwifery programme as they are key components in preparing student midwives for the demands of the unpredictable clinical environment. That said, providing such learning opportunities in a university setting requires approved educational institutions to have the appropriate equipment and manpower to maintain and set up the equipment. The MINT Project (Fraser et al., 2010) highlighted that the demands on midwifery lecturers' time to ensure all students have the chance to observe, practice and be assessed on clinical skills in a safe environment are high. The introduction of specialist support in the form of Laboratory/Clinical Skills Technicians not only makes best use of equipment and time, it also empowers lecturers to focus on facilitating learning.

\section{Laboratory/Clinical Skills Technician: Role and Responsibilities}

Lin is a Laboratory/Clinical Skills Technician for Human Bioscience and Clinical skills within the Faculty of Health and Social Care and her key duties are to support all subject areas with clinical skills and laboratory equipment; however Midwifery is the only discipline where she is actually involved in the simulation and clinical skills sessions as well as setting up and maintaining the equipment (box 1 ).

Equipment, roles and responsibilities

- SimMom (an advanced full body birthing simulator with accurate anatomy and functionality to facilitate multi-professional obstetric training of birth management, with both manual and automatic delivery modes) for normal deliveries, demonstrating artificial rupture of membranes (ARM) and emergency scenarios

- Sim NewB (a newborn simulator designed to help improve neonatal resuscitation) for care of the newborn

- Vaginal examination models for assessing progress in labour

- Suturing equipment

- Resuscitaire

- Basic Life Support mannequins 
- Maintenance, cleaning and infection control procedures for all equipment

- Interactive management of equipment during obstetric emergency management simulation

Box 1

\section{A different perspective on the pros and cons of simulation: Lin's observations}

High tech mannequins have the wow factor and it's amazing to watch the students come in appearing very anxious but within a few minutes they are 'in the zone' and responding like it's a lady in an emergency situation and reassuring her. I love being involved in the shoulder dystocia and breech assessments and practice, as your heart is with the student as they carry out the assessment. I feel I can contribute in a small way by making sure the model works effectively and the baby delivers as it should and that the assessment is consistent for all the students. By making sure the model performs as it should this is one less thing for the student or assessors to worry about and therefore ensuring the scenario runs smoothly, allowing the lecturers to concentrate on assessing the students' performance rather than monitoring the functionality of the technology/equipment.

There are sometimes technical issues which need to be managed such as when equipment loses $\mathrm{Wi}-\mathrm{Fi}$ connection which can negatively impact on the learning experience. Successful simulation 'suspends reality' which is difficult when equipment malfunctions so it is important to be flexible and remember that hightech, complicated and expensive set ups are not the only option for effectively learning. SimMom and Sim NewB demand a lot of time to programme and set up, so more low-tech sessions such as estimating blood loss with a variety of pads and bowls and artificial blood; abdominal examinations; safe injection techniques and venepuncture always get very positive reactions.

\section{The future of simulation and clinical skills in the midwifery pre- registration curriculum}

Standards for pre-registration nursing education have recently been updated to meet the demands of an everchanging contemporary health service and in relation to simulation they stipulate that approved educational institutions must: 
ensure technology enhanced and simulation-based learning opportunities are used effectively and proportionately to support learning and assessment (NMC, 2018:10)

Whilst current Standards for Pre-Registration Midwifery Education state 'the programme must have a variety of learning and teaching strategies, which may include simulation' (NMC, 2009:19), it is expected that new standards, due for implementation in September 2020, will be aligned with those of nursing preregistration programmes in relation to simulation and clinical skills. Consequently, it is important to continue to develop and facilitate well-organised, well-funded and well-evaluated simulation and clinical skills sessions, providing student midwives with a range of learning opportunities. By practising in a 'safe environment' students should then be more confident to transfer these skills into clinical practice. By making best use of lecturers' time and expertise with the support of appropriately trained Laboratory/Clinical Skills Technicians, approved educational institutions can continue to work in partnership with clinical placement providers to link theory to practice and ultimately positively impact on the quality of services and the experiences of service users.

\section{References}

Catling C, Hogan R, Fox D, Cummins A, Michelle K, Sheehan, A (2016) Simulation workshops with first year midwifery students. Nurse Education in Practice 17 109-115

Fraser D, Avis M, (2010) The MINT Project: midwives in teaching. London: Nursing and Midwifery Council (NMC)

Lendahls L, Oscarsson M (2017) Midwifery students' experiences of simulation and skills training. Nurse Education Today 50 12-16

Nursing and Midwifery Council (NMC) (2018) Realising professionalism: Standards for education and training. Part 3: Standards for pre-registration nursing programmes. NMC [Online]. Available from:

https://www.nmc.org.uk/globalassets/sitedocuments/educationstandards/programme-standards-nursing.pdf. [Accessed 26.06.18]

Nursing and Midwifery Council (NMC) (2009) Standards for Pre-registration Midwifery Education. NMC [Online]. Available from:

https://www.nmc.org.uk/globalassets/sitedocuments/standards/nmc-standardsfor-preregistration-midwifery-education.pdf. [Accessed 05.06.18] 
Yuill L (2017) Simulation in midwifery education: not just a passing trend. British Journal of Midwifery 25 (3) 142-143

\section{Authors}

Alison Power (Senior Lecturer in Midwifery)

Linda Clapham (Laboratory/Clinical Skills Technician) 